\title{
PROPAGAÇÃO DA GRAVIOLEIRA POR MINIESTAQUIA ${ }^{1}$
}

\author{
GEÓRGIA ROBERTA GOMES DE FIGUEIRÊDO ${ }^{2}$, FELIPE SILVEIRA VILASBOAS ${ }^{3}$, \\ SÉRGIO JOSÉ RIBEIRO DE OLIVEIRA ${ }^{4}$, GEORGE ANDRADE SODRÉ 5 , \\ CÉLIO KERSUL DO SACRAMENTO 6
}

RESUMO- Avaliou-se o enraizamento de miniestacas de gravioleira (Annona muricata L.), utilizando-se de estacas apicais e subapicais herbáceas coletadas em plantas cultivadas no campo e em casa de vegetação. $\mathrm{O}$ experimento foi conduzido em delineamento inteiramente casualizado, em esquema fatorial $4 \times 2$, sendo 4 tipos de miniestacas (apical herbácea do campo e viveiro, subapical herbácea do campo e de viveiro) e 2 níveis de reguladores de crescimento $\left(0\right.$ e $\left.6.000 \mathrm{mg} \mathrm{kg}^{-1}\right)$, totalizando 8 tratamentos e 3 repetições, com 12 estacas por parcela. As miniestacas foram padronizadas com sete centímetros de comprimento e tratadas ou não com ácido indolbutírico, colocadas em tubetes contendo substrato comercial e mantidas em câmara de nebulização. Aos 80 dias após o estaqueamento, foi observado que as miniestacas subapicais e apicais de casa de vegetação e subapicais do campo apresentaram percentual de enraizamento de $97,3 \%, 88 \%$ e $88 \%$ respectivamente. Não foi detectado efeito da aplicação de AIB no enraizamento das miniestacas.

Termos para indexação: Annona muricata L., enraizamento, ácido indolbutírico.

\section{PROPAGATION OF SOURSOP TREE THROUGH MINICUTTINGS}

\begin{abstract}
It was evaluated the rooting of cuttings of soursop tree (Annona muricata L.) using apical and subapical herbaceous cuttings collected from plants grown in the field and greenhouse. The experiment was conducted in a completely randomized design in a factorial $4 \times 2$, with 4 types of cuttings (apical herbaceous field and greenhouse, subapical herbaceous field and greenhouse) and 2 levels of growth regulators ( 0 and $6,000 \mathrm{mg} \mathrm{kg}^{-1} \mathrm{IBA}$ ), totaling eight treatments and three replicates of 12 cuttings. The cuttings were standardized with seven inches long and treated with 0 or $6,000 \mathrm{mg} \mathrm{kg}^{-1}$ IBA, placed in tubes containing commercial substrate and kept in a mist chamber. At 80 days after striking, it was observed that the subapical and apical cuttings of the greenhouse and subapical cuttings of field showed rooting percentage of $97.3 \%, 88 \%$ and $88 \%$ respectively. There was no detectable effect of IBA on rooting of cuttings.
\end{abstract}

Index terms: Annona muricata L., rooting, indolbutiric acid.

\section{INTRODUÇÃO}

A gravioleira Annona muricata L. é uma espécie frutífera cultivada no Brasil, especialmente nos estados do Nordeste, e a produção é destinada, principalmente, para a agroindústria, onde é utilizada na fabricação de suco, sorvete, compotas e doces cristalizados.

A propagação assexuada apresenta as vantagens de manter a mesma constituição genética da planta e a redução do período vegetativo, mas os produtores têm preferido a propagação seminal da gravioleira devido à dificuldade de sua propagação por enxertia e também porque a gravioleira de origem seminal frutifica antes de dois anos de plantio. Além disso, a maior parte da produção é vendida para agroindústrias, portanto sem exigência em unifor- midade de frutos com relação ao peso e ao formato. (SACRAMENTO et al., 2009). Desse modo, pesquisas têm sido conduzidas na tentativa de propagação vegetativa dessa espécie por estaquia (MARINHO et al., 2007), visando à uniformidade dos plantios e à produção de frutos padronizados para o mercado de frutas in natura.

Entre as técnicas de propagação vegetativa, a miniestaquia, tida como um aprimoramento da técnica de estaquia, tem sido utilizada na multiplicação de diversas espécies vegetais, como cedro-rosa (XAVIER et al., 2003), maracujazeiro- amarelo (CARVALHO et al., 2007), eucalipto (BRONDANI et al., 2008; BORGES et al., 2011), seedlings de araçazeiro e goiabeira (ALTOÉ et al., 2011) e cultivares de goiabeira (MARINHO et al., 2009; ALTOÉ; MARINHO, 2012).

\footnotetext{
(Traballho 030-13). Recebido em: 03-01-2013. Aceito para publicação em: 24-07-2013.

${ }^{2}$ Engenheira Agrônoma, MSc. Universidade Estadual de Santa Cruz, Ilhéus-BA. E-mail: roberta_siegen@hotmail.com

${ }^{3}$ Engenheiro Agrônomo, MSc., Universidade Estadual do Sudoeste da Bahia, Vitoria da Conquista-BA. E-mail: vilasboas@agronomo.eng.br ${ }^{4}$ Engenheiro Agrônomo, DSc. Professsor Titular DCET/UESC, Ilhéus-BA. E-mail: solive2002@gmail.com

${ }^{5}$ Engenheiro Agrônomo, DSc. CEPLAC/CEPEC, Professor Titular, DCAA/UESC, Ilhéus-BA. E-mail: sodre@cepec.gov.br

${ }^{6}$ Engenheiro Agrônomo, DSc.,Professor Pleno DCAA/UESC, Ilhéus-BA.E-mail: celiokersul@gmail.com
} 
O método de propagação por miniestaquia consiste em efetuar a poda dos ramos visando a estimular o lançamento de brotações que são coletadas em intervalos regulares e estaqueadas em casa de vegetação, dando origem às mudas. Em relação ao método de estaquia convencional, a miniestaquia apresenta as vantagens de dispensa do jardim clonal de campo; maior produção de propágulos (miniestacas) por unidade de área; necessidade de menores concentrações ou dispensa de reguladores de crescimento vegetal e redução do tempo de formação da muda (WENDLING; DUTRA, 2008). Além disso, há redução dos custos com transporte e coleta das brotações, maior eficiência das atividades de manejo no jardim miniclonal (irrigação, nutrição, manutenções e controle de pragas e doenças (XAVIER et al., 2003).

Este trabalho teve como objetivo avaliar o enraizamento de diferentes tipos de miniestacas de gravioleira tratadas ou não com AIB.

\section{MATERIAL E MÉTODOS}

O experimento foi conduzido durante o período de outubro de 2011 a janeiro de 2012, na câmara de nebulização do Centro de Pesquisa do Cacau (CEPLAC/CEPEC), Ilhéus-BA.

Miniestacas apicais e subapicais de consistência herbácea foram coletadas em gravioleiras do tipo "Morada", cultivadas no campo e em casa de vegetação. As miniestacas provenientes do campo foram coletadas em plantas de 10 anos de idade, cultivadas no Sítio Santo Antônio, município de Ilhéus-BA, e transportadas em caixas de isopor para a câmara de nebulização. As outras miniestacas foram coletadas em plantas-matrizes de dois anos de idade, mantidas em casa de vegetação, em vasos de $22 \mathrm{dm}^{3}$, preenchidos com substrato à base de casca de Pinus.

As miniestacas foram padronizadas $\mathrm{com} 7 \mathrm{~cm}$ de comprimento, 3 e 4 gemas e duas folhas cortadas ao meio, e a base cortada em bisel.Os tratamentos foram formados por: tipos de estaca e uso de AIB diluído em talco mineral: $\mathrm{AC}$ - apical provenientes do campo sem AIB; ACA - apical provenientes do campo tratadas com AIB (6.000 $\left.\mathrm{mg} \mathrm{kg}^{-1}\right)$; SC - subapical proveniente do campo sem AIB; SCA subapical provenientes do campo, tratadas com AIB; AV - apical proveniente de casa de vegetação sem AIB; AVA - apical proveniente de casa de vegetação, tratada com AIB; SV - subapical proveniente de casa de vegetação, sem AIB; SVA - subapical proveniente de casa de vegetação, tratada com AIB.

Após o preparo, as miniestacas tiveram suas bases tratadas com talco mineral sem AIB ou com $6.000 \mathrm{mg} \mathrm{kg}^{-1}$ de AIB e inseridas na profundidade de $3 \mathrm{~cm}$ em tubetes de $288 \mathrm{~mL}$ contendo o substrato constituído da mistura Holambra ${ }^{\circledR}$ e fibra de coco triturada, na proporção de $1: 1$, enriquecida com Osmocote $^{\circledR}$ (19-06-20) e PGmix ${ }^{\circledR}$ (14-16-18+ micronutrientes), na proporção de $300 \mathrm{~g}$ de cada produto para 120 litros do substrato. Posteriormente, os tubetes foram colocados em bandejas de 54 células, e essas foram levadas para a câmara de nebulização com regime de 10 segundos de aspersão a cada 5 minutos, diariamente das $\mathrm{s} 6$ às $18 \mathrm{~h}$, durante o período de condução do experimento. Durante a coleta, preparo e estaqueamento, as miniestacas foram frequentemente aspergidas com água para evitar a desidratação. A temperatura da câmara de nebulização foi mantida, via controle automático, entre 23 e $28^{\circ} \mathrm{C}$, e a umidade relativa, entre 95 e $99 \%$ durante o período de condução do experimento.

O experimento foi conduzido em delineamento inteiramente casualizado (DIC), em esquema fatorial $4 \times 2$, sendo 4 tipos de miniestacas (apical herbácea do campo, subapical herbácea do campo e de viveiro) e 2 níveis de reguladores de crescimento ( 0 e 6.000 $\mathrm{mg} \mathrm{kg}{ }^{-1}$ de AIB), totalizando 8 tratamentos e 3 repetições, com 12 estacas por parcela.

Foram avaliados, após 80 dias, os seguintes parâmetros: porcentagem de sobrevivência (SOB), porcentagem de enraizamento (ENR) e porcentagem de estacas com folhas remanescentes (FR), número médio de brotos (NB), massa de matéria seca da parte aérea (MSPA), massa de matéria seca das raízes de primeira ordem (MSRP), massa de matéria seca das raízes de segunda ordem (MSRS) e massa de matéria seca total de raízes (MSRT).

Os dados foram submetidos à análise de variância, e as médias, comparadas pelo teste de Tukey, ao nível de 5\% de probabilidade. Os dados de porcentagem foram transformados por arc-sen $(\mathrm{x} / 100)^{1 / 2}$, com a finalidade de proporcionar a normalidade dos erros.

\section{RESULTADOS E DISCUSSÃO}

Foi observada diferença significativa entre os tipos de miniestacas com relação a todas as variáveis avaliados, à exceção do número de brotos (Tabela 1). Vilasboas et al. (2010), trabalhando com diferentes estacas de gravioleira, também não encontraram respostas para número de brotos em experimento com duração de 90 dias. A aplicação de AIB e a interação estaca $\mathrm{x}$ AIB apresentaram efeito significativo para percentagem de folhas remanescentes (Tabela 1). Aparentemente, a aplicação exógena de AIB influenciou no nível interno de auxina, impedindo a redução dos níveis desse regulador e na atividade 
do ácido abscísico. Nesse contexto, durante a senescência das folhas, a síntese de auxinas no limbo foliar diminui consideravelmente, o que promove o rompimento do pecíolo na camada de abscisão.

Na Tabela 2, observa-se que, à exceção das miniestacas $\mathrm{AC}$, as demais apresentaram acima de $70 \%$ de enraizamento, mínimo sugerido por Hartmann et al. (2011) para multiplicação comercial por estaquia.

Pelizza et al. (2011), estudando o comportamento de microestacas de mirtilo retiradas de diferentes porções do ramo, observaram que não houve diferença no enraizamento de estacas apicais e subapicais, porém estacas subapicais apresentaram maiores percentuais em sobrevivência. Segundo esses autores, tal fato está relacionado à maior lignificação do material, posto que microestacas apicais são menos lignificadas e, portanto, mais sensíveis à desidratação e à morte. Além disso, vários fatores podem ter proporcionado menor índice de sobrevivência das miniestacas $\mathrm{AC}$, assim como a exposição da planta às variações climáticas e a um manejo não controlado quando comparado às miniestacas de matrizes cultivadas em casa de vegetação, com um maior controle de pragas, doenças e estado nutricional. As reservas de carboidratos em um nível adequado não só facilitam a emissão de raízes e aumentam o aparato fotossintético, como também elevam a fotossíntese, onde boa parte das reservas se transfere para a base da estaca, contribuindo para a formação dos primórdios radiculares (BASTOS, 2009).

Com relação às variáveis MSRP e MSRS, as miniestacas SC e SV apresentaram, significativamente, os maiores resultados. Segundo Nicoloso et al. (1999) e Hartmann (2011), estacas medianas apresentam maiores teores de carboidratos, quando comparadas a apicais que se correlacionam com maior incremento de raízes de ordem primária. Nicoloso et al. (1999) observaram que estacas de Platanus acerifolia Ait, com maiores diâmetros (estacas medianas), obtiveram maiores incrementos de massa seca de raízes de primeira ordem e de segunda ordem, quando comparadas com estacas herbáceas apicais. Tais parâmetros são de grande importância, pois estacas com elevado incremento de raízes apresentam melhor desempenho quando colocadas no campo (NOOR et al., 2009). Nesse contexto, West (2006) destaca que, dentre as diversas funções do sistema radicular das plantas, destacam-se três papéis fundamentais: manter a planta fixa ao substrato (raízes de primeira ordem), absorver água e sais minerais (raízes de segunda ordem) e produzir hormônios reguladores de crescimento. Adicional- mente, Lopes (2010) considera que a maior parte da absorção de água de nutrientes é feita pelas raízes de segunda ordem, por apresentar maior superfície de absorção. As raízes mais velhas desempenham papel fundamental no transporte dos assimilados pelas raízes finas mais jovens (raízes de segunda ordem), às quais estão conectadas.

Verificou-se que miniestacas SC, AV e SV não apresentaram diferença estatística na ausência de AIB; porém, na presença de AIB, os tratamentos SCA e AVA apresentaram menor queda de folhas (Tabela 3).

No que se refere ao efeito do AIB no enraizamento de espécies lenhosas, Hartmann et al. (2011) relatam que algumas espécies não respondem à aplicação de auxinas. Considerando que o uso de auxinas é tido como fator primordial para o incremento de raízes (FACHINELLO et al., 2005), supõe-se que os níveis de auxina endógena presentes nas estacas de gravioleira, utilizadas neste experimento, foram suficientes para formação de raízes, suposição também apresentada por Nascimento et al. (2011) com o enraizamento de microestacas de mirtileiro. 
TABELA 1 - Resumo da análise de variância para os fatores tipo de miniestacas de gravioleira, AIB e interação em relação à porcentagem de miniestacas sobreviventes (SOB), enraizadas (ENR), com folhas remanescentes (FR), número de brotos (NB), massa seca da parte aérea (MSPA), massa seca de raiz primeira-ordem (MSRP) e segunda ordem (MSRS) e massa seca total de raízes (MSTR).

\begin{tabular}{lccccccccc}
\hline Fatores & GL & SOB & ENR & FR & NB & MSPA & MSRP & MSRS & MSTR \\
\cline { 2 - 10 } & & \multicolumn{7}{c}{ QM } \\
\hline Miniestaca & 3 & $10001,6^{*}$ & $9497,3^{*}$ & $6377,6^{*}$ & $2,5 \mathrm{~ns}$ & $10,8^{*}$ & $6,6^{*}$ & $2,6^{*}$ & $18,2^{*}$ \\
AIB & 1 & $104,1 \mathrm{~ns}$ & $26,0 \mathrm{~ns}$ & $928,7^{*}$ & $6,0 \mathrm{~ns}$ & $0,7 \mathrm{~ns}$ & $0,0 \mathrm{~ns}$ & $0,0 \mathrm{~ns}$ & $0,05 \mathrm{~ns}$ \\
Miniestaca*AIB & 3 & $18,7 \mathrm{~ns}$ & $72,3 \mathrm{~ns}$ & $600,9^{*}$ & $1,9 \mathrm{~ns}$ & $0,4 \mathrm{~ns}$ & $0,32 \mathrm{~ns}$ & $0,1 \mathrm{~ns}$ & $0,8 \mathrm{~ns}$ \\
\hline
\end{tabular}

*: significativo $(\mathrm{P}<0,05)$, ns: não significativo.

TABELA 2- Médias de porcentagem de miniestacas sobreviventes (SOB) e miniestacas enraizadas (ENR) de peso (g) de massa seca de parte aérea (MSPA), massa seca de raízes de primeira ordem (MSRP), massa seca de raízes de segunda ordem (MSRS) e massa seca total de raízes (MSTR) em diferentes tipos de miniestacas de gravioleira provenientes do campo e de casa de vegetação.

\begin{tabular}{|c|c|c|c|c|c|c|}
\hline \multirow[t]{2}{*}{ Miniestacas } & SOB & ENR & MSPA & MSRP & MSRS & MSTR \\
\hline & \multicolumn{2}{|c|}{--------------\%o--------- } & \multicolumn{4}{|c|}{ 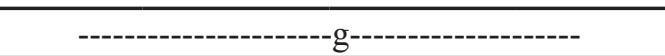 } \\
\hline Apical campo & $12,5 \mathrm{~b}$ & $12,5 \mathrm{~b}$ & $0,11 \mathrm{~b}$ & $0,18 \mathrm{c}$ & $0,12 \mathrm{~b}$ & $0,31 \mathrm{c}$ \\
\hline Subapical campo & $94,3 \mathrm{a}$ & $88,8 \mathrm{a}$ & $0,74 \mathrm{~b}$ & $2,36 \mathrm{a}$ & $1,30 \mathrm{a}$ & $3,66 \mathrm{a}$ \\
\hline Apical c.vegetação & $90,1 \mathrm{a}$ & $88,8 \mathrm{a}$ & $2,72 \mathrm{a}$ & $1,52 \mathrm{~b}$ & $1,23 \mathrm{a}$ & $2,75 \mathrm{~b}$ \\
\hline Subapical c.vegetação & $97,3 \mathrm{a}$ & $97,3 \mathrm{a}$ & $2,71 \mathrm{a}$ & $2,45 \mathrm{a}$ & $1,65 \mathrm{a}$ & $4,11 \mathrm{a}$ \\
\hline$\overline{\mathrm{CV}(\%)}$ & 13,0 & 14,8 & 41,3 & 27,1 & 28,0 & 17,7 \\
\hline
\end{tabular}

Médias seguidas pela mesma letra na coluna não diferem estatisticamente entre si, pelo teste de Tukey, a 5\% de probabilidade.

TABELA 3- Desdobramento da Interação significativa entre tipos de miniestacas de gravioleira e AIB para as médias de porcentagem de miniestacas com folhas remanescentes.

\begin{tabular}{lcc}
\hline Miniestacas (\%) & \multicolumn{2}{c}{$\mathrm{AIB}\left(\mathrm{mg} \mathrm{kg}^{-1}\right)$} \\
\cline { 2 - 3 } & $11,1 \mathrm{Ba}$ & 6.000 \\
\hline Apical campo & $91,6 \mathrm{Aa}$ & $83,3 \mathrm{Ca}$ \\
Subapical campo & $69,3 \mathrm{Aa}$ & $66,6 \mathrm{ABa}$ \\
Apical casa de vegetação & $91,6 \mathrm{Aa}$ & $50,0 \mathrm{Bb}$ \\
Subapical casa de vegetação & \multicolumn{3}{c}{20,4} \\
\hline CV $(\%)$
\end{tabular}

Médias seguidas pela mesma letra maiúscula na coluna e minúscula na linha não diferem estatisticamente entre si, pelo teste de Tukey, a $5 \%$ de probabilidade. 


\section{CONCLUSÕES}

1-A miniestaquia é um método viável para a propagação vegetativa da gravioleira, podendo ser utilizada como propágulos às partes apicais oriundas de plantas-matrizes cultivadas em viveiro e subapicais de plantas-matrizes mantidas no campo e no viveiro.

2-Na avaliação efetuada até os 80 dias, a aplicação de $6.000 \mathrm{mg} \mathrm{kg}^{-1}$ de AIB não apresenta efeito no enraizamento de miniestacas de gravioleira.

\section{REFERÊNCIAS}

ALTOÉ, J.A.; MARINHO, C.S. Miniestaquia seriada na propagação da goiabeira 'Paluma'. Revista Brasileira de Fruticultura, Jaboticabal, v. 34, n. 2, p. 572-580, 2012.

ALTOÉ, J.A.; MARINHO, C.S.; TERRA, M.I.C.; BARROSO, D.G., Propagação do araçazeiro e goiabeira via miniestaquia de material juvenil. Bragantia, Campinas. v. 70, n. 2, p. 312-318, 2011.

BASTOS, D. C.; SCARPARE FILHO, J.A. ; FATINANSI, J. C. ; PIO, R. Influência da idade biológica da planta matriz e do tipo de estaca caulinar de caramboleira na formação de raízes adventícias. Ciência e Agrotecnologia, Lavras, v. 33, p. 19151918, 2009.

BORGES, S. R; XAVIER, A; OLIVEIRA, L. S; MELO, L. A; ROSADO, A. M. Enraizamento de miniestacas de clones híbridos de Eucalyptus globulus. Revista Árvore, Viçosa, MG, v. 35, n. 3, p. 425-434, 2011.

BRONDANI, G. E.; WENDLING, I.; ARAUJO, M. A.; PIRES, P. P. Ácido indolbutírico em gel para o enraizamento de miniestacas de Eucalyptus benthamii Maiden \& Cambage x Eucalyptus dunnii Maiden. Scientia Agraria, Curitiba, v. 9, n. 2, p. 153-158, 2008

CARVALHO, R.I.N.; SILVA, I.D.; FAQUIM, R. Enraizamento de miniestacas de maracujazeiro amarelo. Semina, Londrina, v.28, n.3, p.387-392, 2007.
FACHINELLO, J. C.; HOFFMANN, A.; NACHTIGAL, J. C.; KERSTEN, E. Propagação vegetativa por estaquia. In: FACHINELLO, J. C.; HOFFMANN, A.; NACHTIGAL, J. C. Propagação de plantas frutíferas. Brasília: Embrapa Informação Tecnológica, 2005, p. 69-109.

HARTMANN, H.T; KESTER, D.E; DAVIES JR, F.T; GENEVE, R.L. Hartmann and Kester's Plant propagacion: principles and practices. $8^{\text {th }} \mathrm{ed}$. New Jersey: Prentice Hall, 2011. 915 p.

LOPES, V. G.; SCHUMACHER, M. V.; CALIL, F. N.; VIERA, M.; WITSCHORECK, R. Quantificação de raízes finas em um povoamento de Pinus taeda L. e uma área de campo em cambará do Sul (RS). Ciência Florestal, Santa Maria, v. 20, p. 569-578, 2010 .

MARINHO, C.S.; MILHEN, L.M.A., ALTOÉ, J.A., BARROSO, D.S., POMMER, C.V. Propagação da goiabeira por miniestaquia. Revista Brasileira de Fruticultura, Jaboticabal, v. 31, n. 2, p. 607-611, 2009.

MARINHO, G. A.; LEMOS, E. E. P.; SANTIAGO, A. D.; MOURA FILHO, G.; REZENDE, L. P. Enraizamento de estacas de gravioleira (Annona muricata L.). Ciência Agrícola, Rio Largo, v. 8, n. 1, p. 19-23, 2007

NASCIMENTO, D. C.; SCHUCH, M. W.; PEIL, R. M. N. Enraizamento de microestacas de mirtileiro provenientes de minijardim clonal semi-hidropônico. Revista Brasileira de Fruticultura, Jaboticabal, v. 33, n. 4, p. 1251-1256, 2011.

NICOLOSO, F. T.; LAZZARI, M.; FORTUNATO, R. P. Propagação vegetativa de Platanus acerifolia Ait.: (I) Efeito de tipos fisiológicos das estacas e épocas de coleta no enraizamento de estacas. Ciência Rural, Santa Maria, v. 29, n. 3, p. 479-485, 1999.

NOOR, C. N. A.; THOHIRAH, L. A.; ABDULLAH, N. A. P.; KHIDIR, M. O. Improvement on rooting quality of Jatropha curcas using indole butyric acid (IAB). Research Journal of Agriculture and Biological Sciences, Jordan, v. 5, n. 4, p. 338-343, 2009. 
PELIZZA, T. R.; DAMIANI, C. R.; RUFATO, A. R.; SOUZA, A. L. K.; RIBEIRO, M. F.; SCHUCH, M. W. Microestaquia em mirtileiro com diferentes porções do ramo e substratos. Bragantia, Campinas, v. 70, n. 2, p.319-324, 2011

SACRAMENTO, C.K., MOURA, J.I.L.. COELHO JR., E. Graviola. In: SANTOS-SEREJO, J. et al. (Eds) Fruticultura Tropical: frutas regionais e exóticas, Embrapa. 2009, p. 95-132.

VILASBOAS, F.S. ; SODRÉ, G.A. ; OLIVEIRA, S. J. R. ; SACRAMENTO, C. K. Fenologia e propagação vegetativa da gravioleira (Annona muricata L.) na região sul da Bahia.. In: REUNIÃO ANUAL DA SBPC, 62., 2010, Natal. Anais... Natal: UFRN, 2010. Disponível em: $<$ http://www.sbpenet. org.br/livro/62ra/resumos/resumos $>$.
XAVIER, A.; SANTOS, G. A.; WENDLING, I.; OLIVEIRA, M. L. Propagação vegetativa de cedrorosa por miniestaquia. Revista Árvore, Viçosa, MG, v. 27 , p. 139-143, 2003.

WENDLING, I.; DUTRA, L. F. Solução nutritiva para condução de minicepas de erva-mate (Ilex paraguariensis St. Hil.). Colombo: Embrapa Florestas, 2008. 5 p. (Circular Técnica, 157)

WEST, P. W. Growing plantation forests. Heidelberg: Springer-Verlag, 2006. 304 p. 